\title{
The Influence of Chemical Composition on Shape Memory Effect of TiNi Bulk Alloy Produced by Mechanical Alloying
}

\author{
T. Saito and A. Takasaki \\ Shibaura Institute of Technology, 3-7-5 Toyosu, Koto-ku, Tokyo 135-8548, Japan \\ Fax:+81-3-5859-8001, e-mail: m408030@shibaura-it.ac.jp
}

\begin{abstract}
Three kinds of elemental powders consisted of $\mathrm{Ti}$ and $\mathrm{Ni}$, with different chemical compositions, $\mathrm{Ti}_{50} \mathrm{Ni}_{50}, \mathrm{Ti}_{45} \mathrm{Ni}_{55}$ and $\mathrm{Ti}_{55} \mathrm{Ni}_{45}$, were mechanically alloyed for $30 \mathrm{~h}$ by a planetary ball mill, compacted, sintered at $973 \mathrm{~K}$ and annealed at several temperatures, $673 \mathrm{~K}$, $773 \mathrm{~K}$ and $873 \mathrm{~K}$, and the martensitic transformation behaviors for those bulk samples were investigated. All three samples turned into amorphous state after mechanical alloying for $30 \mathrm{~h}$. After compacting, sintering and annealing, however, TiNi (B2) phase with a small amount of $\mathrm{Ti}_{2} \mathrm{Ni}$ phase formed in the $\mathrm{Ti}_{50} \mathrm{Ni}_{50}$ sample, while TiNi (B2), $\mathrm{Ti}_{2} \mathrm{Ni}$ and $\mathrm{TiNi}_{3}$ phases formed in $\mathrm{Ti}_{45} \mathrm{Ni}_{55}$, and TiNi (monoclinic), $\mathrm{Ti}_{2} \mathrm{Ni}$ and $\mathrm{Ti}_{3} \mathrm{Ni}_{4}$ phases in $\mathrm{Ti}_{55} \mathrm{Ni}_{45}$. The fraction of $\mathrm{Ti}$ in all the samples was reduced by approximately 1 at $\%$ after a series of fabrication processes, suggesting that mechanical alloying (MA) process contributed to the phenomenon. Martensitic transformation behavior was observed in all the samples after a series of fabrication processes. Several precipitated phases influenced the martensitic transformation behavior, temperature and enthalpy for the transformation, suggesting that the precipitated phases have possibility to control martensitic transformation temperature. The martensitic transformation behavior was also dependent on annealing temperature.

Key words: TiNi shape memory alloy, chemical compositions, martensitic transformation, mechanical alloying, current sintering
\end{abstract}

\section{INTRODUCTION}

TiNi alloy is widely used for several industrial fields because of their good mechanical properties, corrosion resistance and fascinating behavior called as shape memory effect due to the thermo-elastic martensitic transformation. In terms of using TiNi shape memory alloy in several industrial fields, fabrication processes of the alloy are imperative to be investigated. Powder metallurgy has been attracted much attention, when compared to the conventional way, because of simplicity, cheapness and being able to apply complex shape as near-net-shape product. Mechanical alloying (MA) has some advantages to produce intermetallic compounds like TiNi [1]. It helps to change the local chemical compositions in the alloys and to form a near-net-shape product, after sintering the powders. In this study, powders with three kinds of chemical composition width consisted of $\mathrm{Ti}$ and $\mathrm{Ni}, \mathrm{Ti}_{50} \mathrm{Ni}_{50}, \mathrm{Ti}_{45} \mathrm{Ni}_{55}$ and $\mathrm{Ti}_{55} \mathrm{Ni}_{45}$ were mechanically alloyed by a planetary ball mill, sintered and annealed, and the martensitic transformation behavior for those bulk samples were investigated.

\section{EXPERIMENTAL PROCEDURE}

Commercially pure $\mathrm{Ti}(99.9 \%)$ and $\mathrm{Ni}(99.9 \%)$ powders were used in this study. Three kinds of different chemical compositions, $\mathrm{Ti}_{50} \mathrm{Ni}_{50}, \mathrm{Ti}_{45} \mathrm{Ni}_{55}$ and $\mathrm{Ti}_{55} \mathrm{Ni}_{45}$ were mechanically alloyed by a planetary ball mill with stainless steel balls in an argon atmosphere in order to minimize the oxygen contamination during MA. The ball-to-powder weight ratio was approximately $8: 1$. The maximum milling time was $30 \mathrm{~h}$. The alloying period of $30 \mathrm{~min}$ was alternated with an equal rest time in order to avoid increasing temperature. The powder after MA was compacted and sintered at $973 \mathrm{~K}$ for $10 \mathrm{~min}$ under vacuum condition $(2 \mathrm{~Pa})$ at a pressure of $20 \mathrm{MPa}$. The sintered bulk sample was then annealed in a furnace at several temperatures $(673 \mathrm{~K}, 773 \mathrm{~K}$ and $873 \mathrm{~K})$ for $1 \mathrm{~h}$ under a high vacuum condition $\left(10^{-3} \mathrm{~Pa}\right)$. The phases of the samples were determined by X-ray diffraction (XRD) measurement using $\mathrm{Cu}-\mathrm{K} \alpha$ radiation at $20 \mathrm{kV}$ and $40 \mathrm{~mA}$. The martensitic transformation behavior of the samples was observed by differential scanning calorimetry (DSC). The chemical compositions of the samples were determined by energy-dispersive X-ray spectroscopy (EDX).

\section{RESULTS AND DISCUSSION}

Fig. 1 shows the XRD patterns for $\mathrm{Ti}_{50} \mathrm{Ni}_{50}$ powder after several alloying times, indicating that elemental powders, $\mathrm{Ti}$ and $\mathrm{Ni}$, remain at the early stage of mechanical alloying, however, the elemental powders turned into amorphous state after MA for $30 \mathrm{~h}$. XRD patterns for other powder samples, $\mathrm{Ti}_{45} \mathrm{Ni}_{55}$ and $\mathrm{Ti}_{55} \mathrm{Ni}_{45}$, also showed the similar patterns after MA for $30 \mathrm{~h}$. Thus, all three kinds of powder samples, $\mathrm{Ti}_{50} \mathrm{Ni}_{50}, \mathrm{Ti}_{45} \mathrm{Ni}_{55}$ and $\mathrm{Ti}_{55} \mathrm{Ni}_{45}$, turned into amorphous state after MA for $30 \mathrm{~h}$. Fig. 2, 3 and 4 shows XRD patterns for $\mathrm{Ti}_{50} \mathrm{Ni}_{50}, \mathrm{Ti}_{45} \mathrm{Ni}_{55}$ and $\mathrm{Ti}_{55} \mathrm{Ni}_{45}$ samples, respectively, after sintering at $973 \mathrm{~K}$ and annealing at $773 \mathrm{~K}$. After sintering and annealing, TiNi (B2) phase with a small amount of $\mathrm{Ti}_{2} \mathrm{Ni}$ phase formed in the $\mathrm{Ti}_{50} \mathrm{Ni}_{50}$ sample, while TiNi (B2), $\mathrm{Ti}_{2} \mathrm{Ni}$ and $\mathrm{TiNi}_{3}$ phase formed in the $\mathrm{Ti}_{45} \mathrm{Ni}_{55}$ sample, and $\mathrm{TiNi}$ (monoclinic), $\mathrm{Ti}_{2} \mathrm{Ni}$ and $\mathrm{Ti}_{3} \mathrm{Ni}_{4}$ phases in the $\mathrm{Ti}_{55} \mathrm{Ni}_{45}$ sample. 


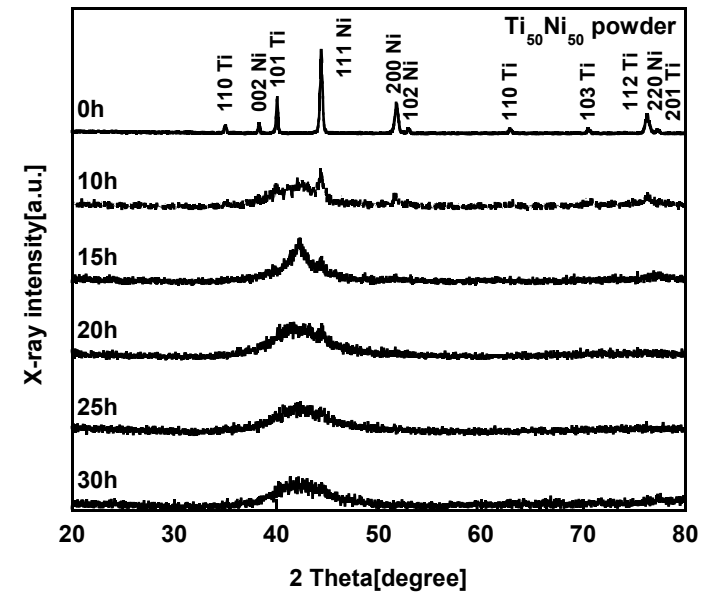

Fig. 1 XRD patterns for $\mathrm{Ti}_{50} \mathrm{Ni}_{50}$ powders after several alloying time.

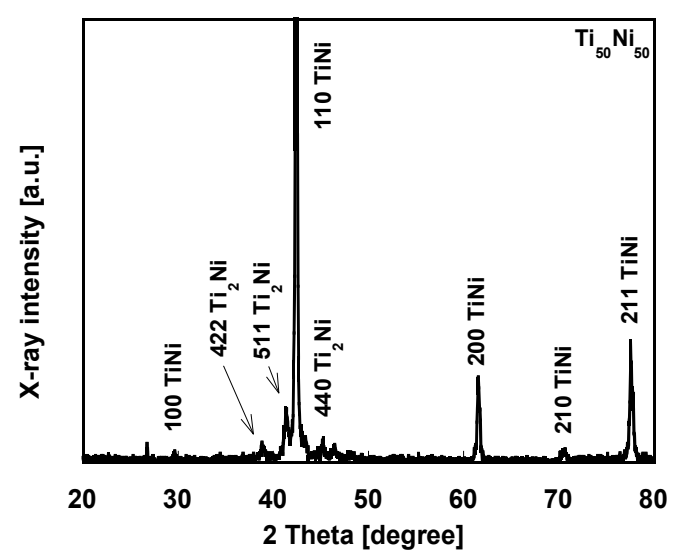

Fig. 2 XRD pattern for $\mathrm{Ti}_{50} \mathrm{Ni}_{50}$ sample after sintering at $973 \mathrm{~K}$ and annealing at $773 \mathrm{~K}$.

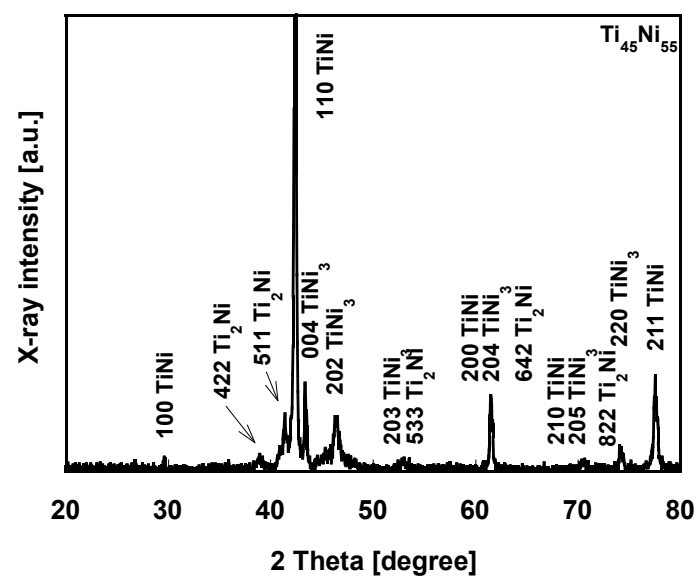

Fig. 3 XRD pattern for $\mathrm{Ti}_{45} \mathrm{Ni}_{55}$ sample after sintering $973 \mathrm{~K}$ and annealing at $773 \mathrm{~K}$.

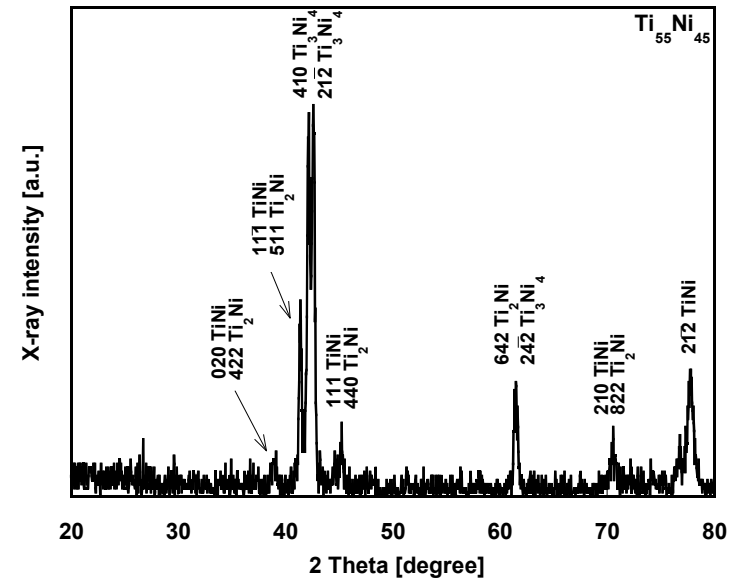

Fig.4 XRD pattern for $\mathrm{Ti}_{55} \mathrm{Ni}_{45}$ sample after sintering at $973 \mathrm{~K}$ and annealing at $773 \mathrm{~K}$.

Chemical compositions of each sample measured by EDX after a series of fabrication processes were shown in Table. I. It is indicated that fraction of Ti was reduced by approximately $1 \mathrm{at} \%$ after a series of fabrication processes. MA process contributed to the phenomenon because the powders heavily adhered to the vial inner wall as well as the surface of the stainless ball after MA. It leads to change the chemical compositions and produce precipitated phases.

Table. I Chemical compositions of each sample after a series of fabrication processes.

\begin{tabular}{cc}
\hline composition before MA & Precise compositions \\
\hline $\mathrm{Ti}_{45} \mathrm{Ni}_{55}$ & $\mathrm{Ti}_{44.1} \mathrm{Ni}_{55.9}$ \\
\hline $\mathrm{Ti}_{50} \mathrm{Ni}_{50}$ & $\mathrm{Ti}_{48.7} \mathrm{Ni}_{51.3}$ \\
\hline $\mathrm{Ti}_{55} \mathrm{Ni}_{45}$ & $\mathrm{Ti}_{54.2} \mathrm{Ni}_{45.8}$ \\
\hline
\end{tabular}

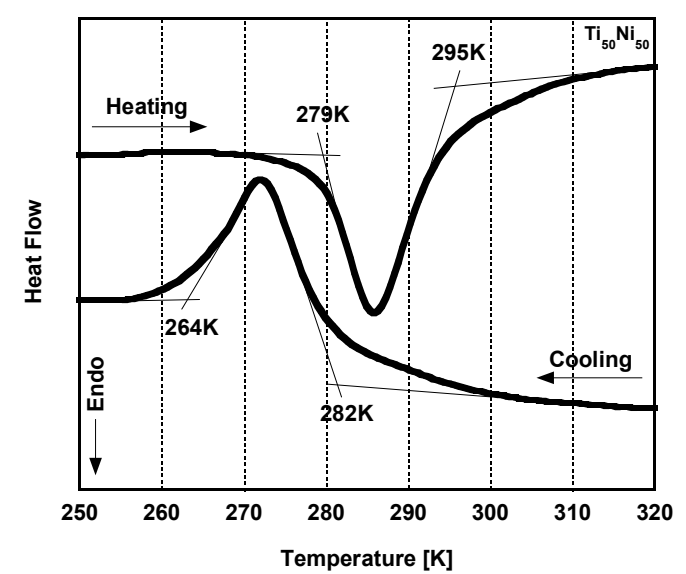

Fig.5 DSC curves for equiatomic $\mathrm{Ti}_{50} \mathrm{Ni}_{50}$ sample. 


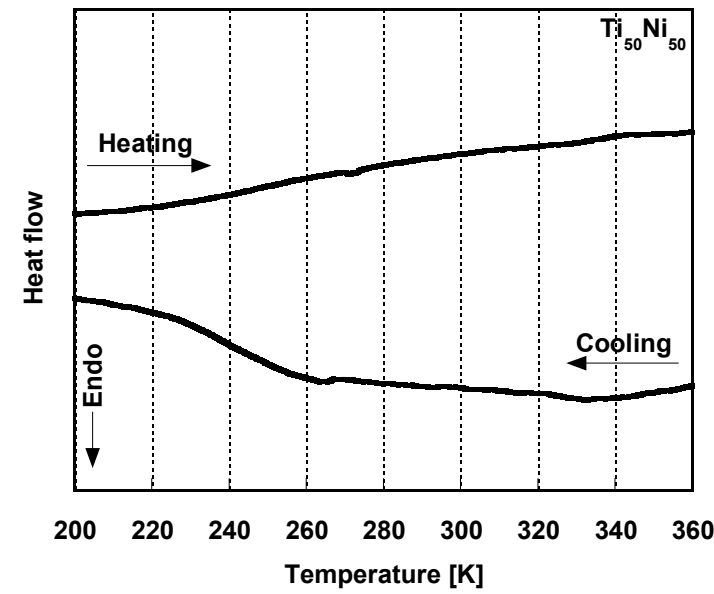

Fig.6 DSC curves for equiatomic $\mathrm{Ti}_{50} \mathrm{Ni}_{50}$ sample before annealing (after sintering).

DSC curves for the $\mathrm{Ti}_{50} \mathrm{Ni}_{50}$ sample after a series of fabrication processes are shown in Fig.5. It is indicated that clear peaks, martensitic transformation (exothermic) and reverse transformation (endothermic), were observed in the $\mathrm{Ti}_{50} \mathrm{Ni}_{50}$ sample. A transformation temperature width between $\mathrm{M}_{\mathrm{s}}$ and $\mathrm{M}_{\mathrm{f}}$ or $\mathrm{A}_{\mathrm{s}}$ and $\mathrm{A}_{\mathrm{f}}$ was approximately $20 \mathrm{~K}$, where $M_{s}$ is the martensitic transformation start temperature, $\mathrm{M}_{\mathrm{f}}$ the martensitic transformation finish temperature, $A_{s}$ the reverse transformation start temperature, and $\mathrm{A}_{\mathrm{f}}$ the reverse transformation finish temperature. Fig.6 shows DSC curves for equiatomic $\mathrm{Ti}_{50} \mathrm{Ni}_{50}$ sample before annealing (after sintering), which indicates that no martensitic transformation behavior was observed before annealing (after sintering), although the martensitic transformation behavior was observed in the sample after annealing. This suggests that the annealing process is important to produce phase homogenization in the sample.

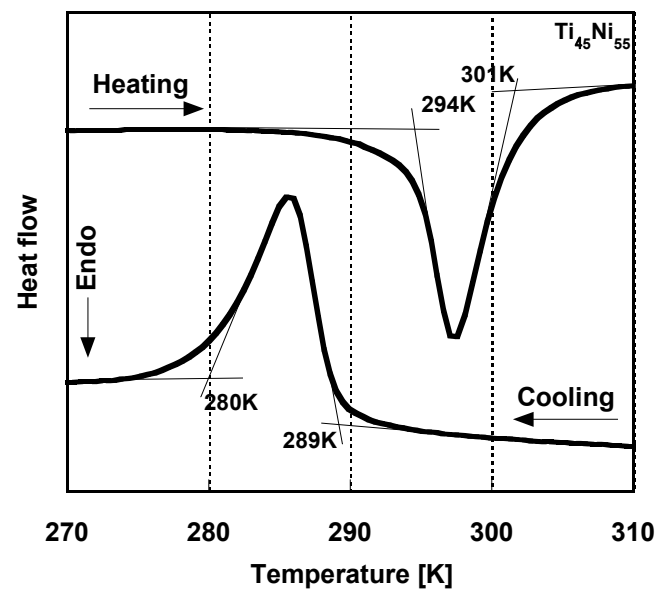

Fig.7 DSC curves for $\mathrm{Ti}_{45} \mathrm{Ni}_{55}$ sample.
DSC curves for $\mathrm{Ti}_{45} \mathrm{Ni}_{55}$ and $\mathrm{Ti}_{55} \mathrm{Ni}_{45}$ samples after a series of fabrication processes are shown in Fig.7 and 8 respectively, showing clear peaks for both $\mathrm{Ti}_{45} \mathrm{Ni}_{55}$ and $\mathrm{Ti}_{55} \mathrm{Ni}_{45}$ samples. A transformation temperature width of $\mathrm{Ti}_{45} \mathrm{Ni}_{55}$ sample was less than $10 \mathrm{~K}$, which is smaller than that of $\mathrm{Ti}_{50} \mathrm{Ni}_{50}$ sample, showing better temperature response. On the other hand, two-stage transformation was confirmed in $\mathrm{Ti}_{55} \mathrm{Ni}_{45}$ sample, whereas no such behavior was observed in other samples $\left(\mathrm{Ti}_{45} \mathrm{Ni}_{55}\right.$ and $\mathrm{Ti}_{50} \mathrm{Ni}_{50}$ ). In the case of $\mathrm{Ti}_{55} \mathrm{Ni}_{45}$ sample, $\mathrm{Ti}_{3} \mathrm{Ni}_{4}$ phase formed after sintering and annealing, but, this phase was not formed in $\mathrm{Ti}_{45} \mathrm{Ni}_{55}$ and $\mathrm{Ti}_{50} \mathrm{Ni}_{50}$ samples as mentioned earlier, which suggests that the $\mathrm{Ti}_{3} \mathrm{Ni}_{4}$ phase may contribute to the two-stage transformation.

Fig.9 shows DSC curves for chemical compositions, $\mathrm{Ti}_{45} \mathrm{Ni}_{55}, \mathrm{Ti}_{50} \mathrm{Ni}_{50}$ and $\mathrm{Ti}_{55} \mathrm{Ni}_{45}$ sample after a series of fabrication processes, respectively. It is indicated that several precipitated phases in TiNi influenced martensitic transformation behavior, transformation temperature and enthalpy, which means several precipitated phases have possibility to control martensitic transformation temperature of TiNi shape memory alloy. In terms of martensitic transformation enthalpy, $\mathrm{Ti}_{50} \mathrm{Ni}_{50}$ sample had relatively low enthalpy compared to the others. Several precipitated phases interrupt the transformation. Thus, the transformation enthalpy of $\mathrm{Ti}_{45} \mathrm{Ni}_{55}$ and $\mathrm{Ti}_{55} \mathrm{Ni}_{45}$ sample was larger than that of $\mathrm{Ti}_{50} \mathrm{Ni}_{50}$ sample.

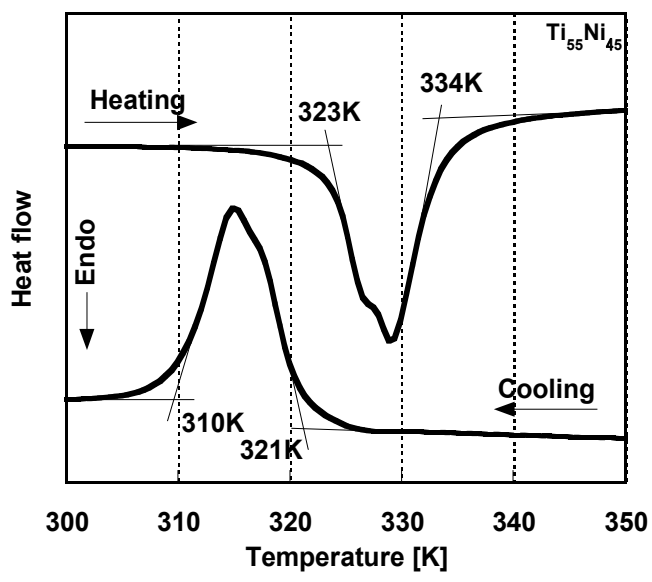

Fig.8 DSC curves for $\mathrm{Ti}_{55} \mathrm{Ni}_{45}$ sample.

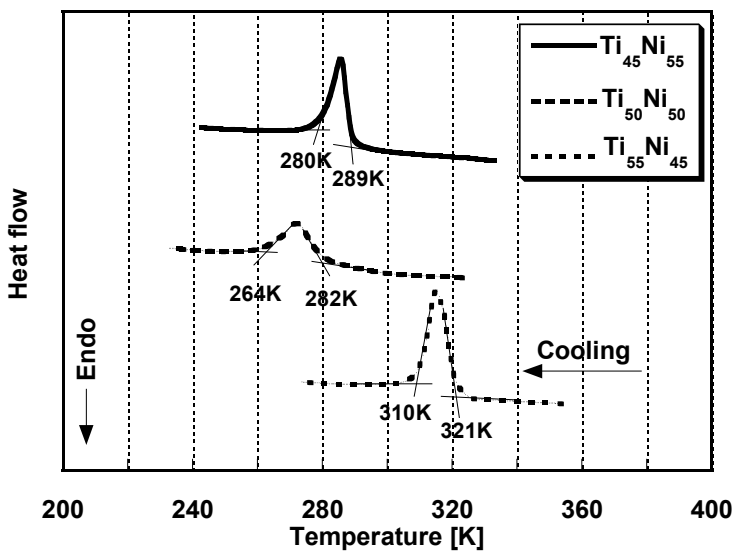

Fig.9 DSC curves for chemical composition, $\mathrm{Ti}_{45} \mathrm{Ni}_{55}$, $\mathrm{Ti}_{50} \mathrm{Ni}_{50}$ and $\mathrm{Ti}_{55} \mathrm{Ni}_{45}$ respectevely. 
DSC curves for $\mathrm{Ti}_{50} \mathrm{Ni}_{50}$ sample after sintering at $773 \mathrm{~K}$ and at different annealing temperatures, $673 \mathrm{~K}$, $773 \mathrm{~K}$ and $873 \mathrm{~K}$ are shown in Fig.10. Martensitic transformation temperature and enthalpy are linearly depended on annealing temperature. The martensitic transformation temperature was lowered with increasing annealing temperature, while the martensitic transformation enthalpy was decreased.

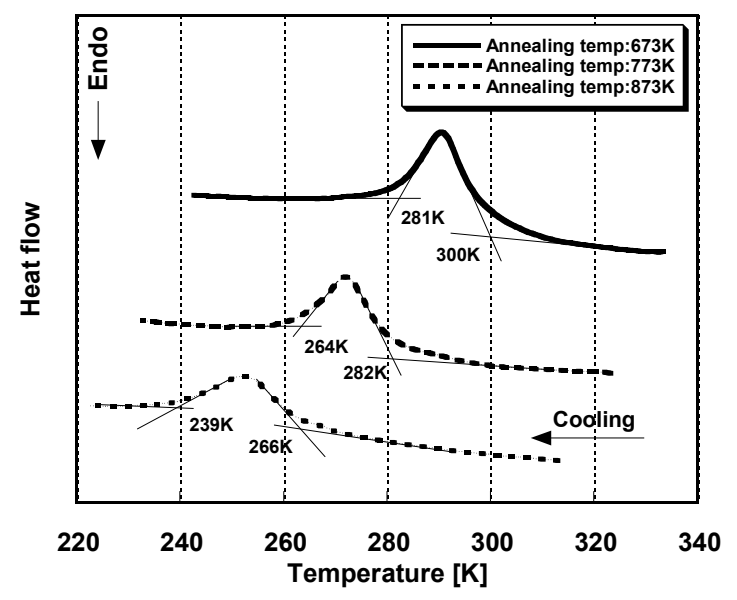

Fig.10 DSC curves for $\mathrm{Ti}_{50} \mathrm{Ni}_{50}$ sample annealed at different temperatures, $673 \mathrm{~K}, 773 \mathrm{~K}$ and $873 \mathrm{~K}$.

\section{CONCLUSIONS}

Three kinds of powders consisted of $\mathrm{Ti}$ and $\mathrm{Ni}$, with different chemical compositions, $\mathrm{Ti}_{50} \mathrm{Ni}_{50}, \mathrm{Ti}_{45} \mathrm{Ni}_{55}$ and $\mathrm{Ti}_{55} \mathrm{Ni}_{45}$ were mechanically alloyed by a planetary ball mill, compacted, sintered and annealed, and the martensitic transformation behavior for those bulk samples was investigated. The results are summarized as follows:

1. The martensitic transformation behavior was observed in the samples after a series of fabrication processes for all compacted samples.

2. Several precipitated phases influenced martensitic transformation behaviors like transformation temperature and the enthalpy.

3. The martensitic transformation temperature was changed after annealing of several temperatures.

\section{REFERENCES}

[1] A. Takasaki, Phys. Stat. Sol. (a), 169, (1998), 183-191

(Received December 17, 2008; Accepted May 11, 2009) 